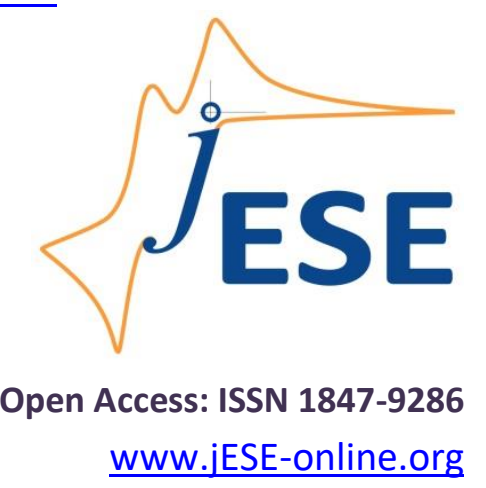

Original scientific paper

\title{
Electroactive properties of a new azulene thioxo-imidazolidin-4-one ligand for modified electrodes
}

\author{
Elena Diacu ${ }^{1}$, Adinuta Paun ${ }^{1}$, Veronica Anastasoaie ${ }^{1}$, Georgiana-Luiza Arnold-Tatu ${ }^{1}$, \\ Liviu Birzan², Eleonora-Mihaela Ungureanu ${ }^{1, \bigotimes}$ \\ ${ }^{1}$ University "Politehnica" of Bucharest, Faculty of Applied Chemistry and Material Science, \\ 1-7 Gheorghe Polizu, 011061, Bucharest, Romania \\ ${ }^{2}$ Romanian Academy, Institute of Organic Chemistry "C. D. Nenitzescu", Spl. Independentei, 202B, \\ 060023-Bucharest, 35 P.O. Box 108, Romania
}

Corresponding author: ${ }^{\bowtie}$ eleonoramihaelaungureanu@gmai.com; Tel.: +40 214023977

Received: September 19, 2019; Revised: October 7, 2019; Accepted: October 17, 2019

\begin{abstract}
The electrochemical characterization of a new synthesized azulene compound (Z)-5-((5-isopropyl-3,8-dimethylazulen-1-yl)methylene)-2-thioxoimidazolidin-4-one (L) using cyclic voltammetry, differential pulse voltammetry and rotating disk electrode is presented. Chemically modified electrodes were obtained by successive scanning or by controlled potential electrolysis using different electrode potentials or charges. The new modified electrodes were tested in solutions containing different concentrations of the following heavy metals: cadmium, lead, mercury and copper. A good analytical response was obtained for $\mathrm{Pb}^{2+}$.
\end{abstract}

\section{Keywords}

(Z)-5-((5-isopropyl-3,8-dimethylazulen-1-yl)methylene)-2-thioxo-imidazolidin-4-one, electrochemical characterization, chemically modified electrodes, heavy metals recognition

\section{Introduction}

Azulenes have a five - member (electron - rich) cyclic moiety connected to a seven - member (electron - poor) cyclic moiety. Azulene derivatives present an irreversible electrooxidation, and an irreversible [1] or quasi - reversible reduction [2]. There are many studies performed on the properties of azulene polymers formed by electrochemistry. They have characteristics very similar to those chemically synthesized. Researches were carried out to prepare polyazulene films or metal complexes of azulene derivatives [3-5]. Our research team is working on developing sensors based on azulene derivatives for heavy metals recognition [6-8].

Classical techniques used for the determination of heavy metal ions are: spectrometry (graphite furnace atomic absorption spectroscopy, flame atomic absorption spectroscopy, inductively coupled plasma optical emission spectrometry), and chromatography (gas chromatography, high performance 
liquid chromatography). These methods are precise, but they require complex equipment (expensive), and well-trained staff [9-13] to maintain and use them. Stripping analysis using chemically modified electrodes (CMEs) is an alternative to these classical methods, offering the following advantages: higher selectivity due to the specific interactions between the metal ions and complexing matrix, limited chemical interferences, and capability to sense metals as $\mathrm{Hg}$ or $\mathrm{Ag}[5,14]$.

The present work reports the study of electroactive properties of (Z)-5-((5-isopropyl-3,8-dimethylazulen-1-yl)methylene)-2-thioxo-imidazolidin-4-one (L), in view of building new sensors for heavy metals recognition. The study of its electroactive properties aims to get the values of the most important parameters for the electrochemical preparation of chemically modified electrodes based on this ligand. The structure of this new azulene thioxo-imidazolidin-4-one derivative is given below (Fig. 1). The study performed using cyclic voltammetry, differential pulse voltammetry and rotating disk electrode was a subject of a PhD thesis [15] defended in our group.

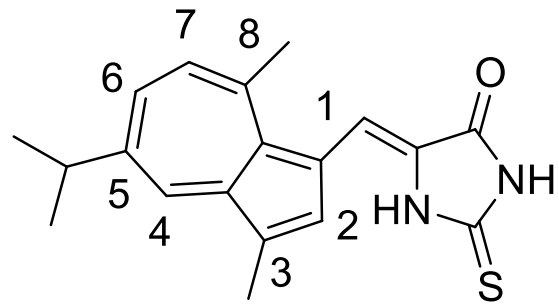

Figure 1. Structure of

(Z)-5-((5-isopropyl-3,8-dimethylazulen-1-yl)methylene)-2-thioxo-imidazolidin-4-one

\section{Experimental}

This azulene derivative (L) was synthesized according to the previously published procedure [16].

Acetonitrile (Sigma Aldrich, electronic grade $99.999 \%$ trace metals) and tetra-N-butylammonium perchlorate (TBAP) (Fluka, puriss, electrochemical grade $>99 \%$ ) were used as solvent and supporting electrolyte, respectively, without further purifications.

Sodium acetate (Roth, $99.99 \%$ ) and acetic acid (Fluka, >99.0\%, trace select) were used for preparing acetate buffer solution. $\mathrm{Pb}\left(\mathrm{NO}_{3}\right)_{2}$ (Sigma-Aldrich, $+99.99 \%$ trace metal basis), $\mathrm{Cd}\left(\mathrm{NO}_{3}\right)_{2} \times$ $\times 4 \mathrm{H}_{2} \mathrm{O}$ (Sigma-Aldrich, $+99.0 \%$ ), $\mathrm{Cu}\left(\mathrm{CH}_{3} \mathrm{COO}\right)_{2} \times \mathrm{H}_{2} \mathrm{O}$ (Fluka, $+99.0 \%$ ) and $\mathrm{Hg}\left(\mathrm{CH}_{3} \mathrm{COO}\right)_{2}$ (SigmaAldrich, $+99.99 \%$ trace metal basis) were used as received. Distilled water was obtained using a Millipore Direct - Q 3UV water purification system $(18.2 \mathrm{M} \Omega \mathrm{cm})$.

The electrochemical experiments were performed using a PGSTAT 12 AUTOLAB potentiostat connected to a three-electrode cell. $\mathrm{Ag} / 10 \mathrm{mM} \mathrm{AgNO}_{3}$ in $0.1 \mathrm{M} \mathrm{TBAP}, \mathrm{CH}_{3} \mathrm{CN}$, was used as reference electrode, and a platinum wire served as counter-electrode. The working electrode was a glassy carbon disk ( $3 \mathrm{~mm}$ diameter) polished with diamond paste $(0.25 \mu \mathrm{m})$ and cleaned with the acetonitrile before each experiment.

Cyclic voltammetry $(\mathrm{CV})$ was run usually at $0.1 \mathrm{~V} / \mathrm{s}$ or at different scan rates $(0.1-1.0 \mathrm{~V} / \mathrm{s})$ to see the influence of this parameter on CV curves. Differential pulse voltammetry (DPV) was performed with a scan rate of $0.01 \mathrm{~V} / \mathrm{s}$ with a pulse height of $0.025 \mathrm{~V}$ and a step time of $0.2 \mathrm{~s}$. RDE curves were usually recorded at $0.01 \mathrm{~V} / \mathrm{s}$, and at different rotation rates.

All potentials were referred to the potential of ferrocene/ferrocenium redox couple ( $\left.\mathrm{Fc} / \mathrm{Fc}^{+}\right)$ which in our conditions was $+0.07 \mathrm{~V}$.

Electrochemical experiments of heavy metal ions detection have been performed in $0.1 \mathrm{M}$ acetate buffer ( $\mathrm{pH}$ 5.5) solution as the supporting electrolyte. Heavy metal ion solutions of different concentration $\left(10^{-4}-10^{-8} \mathrm{M}\right)$ were freshly prepared by successive dilutions from a stock solution $\left(10^{-2} \mathrm{M}\right)$ in water. All experiments were performed at room temperature $\left(25^{\circ} \mathrm{C}\right)$ under argon atmosphere. 


\section{Results and discussion}

\section{Electrochemical characterization of $\boldsymbol{L}$}

The electrochemical behavior has been studied by CV, DPV and RDE in $0.1 \mathrm{M} \mathrm{TBAP}, \mathrm{CH}_{3} \mathrm{CN}$ using millimolar solutions of $\mathbf{L}$. All the curves were recorded starting from the stationary potential. CV and DPV anodic and cathodic curves obtained on glassy carbon electrode for different concentrations of $\mathbf{L}$ in $0.1 \mathrm{M} \mathrm{TBAP}, \mathrm{CH}_{3} \mathrm{CN}$ are presented in Figure 2. The current peaks are increasing with $\mathbf{L}$ concentration. Two significant peaks (a1, a2) can be seen in the anodic domain and four peaks (c1 - c4) in the cathodic domain from the DPV curves.

$\mathrm{CV}$ curves show the two main peaks (a1 and a2). The peak a4 can be attributed to some adsorption processes, as the current does not systematically increase with the ligand concentration. In the reduction domain, only three peaks are clearly defined (c1, c2, c3).

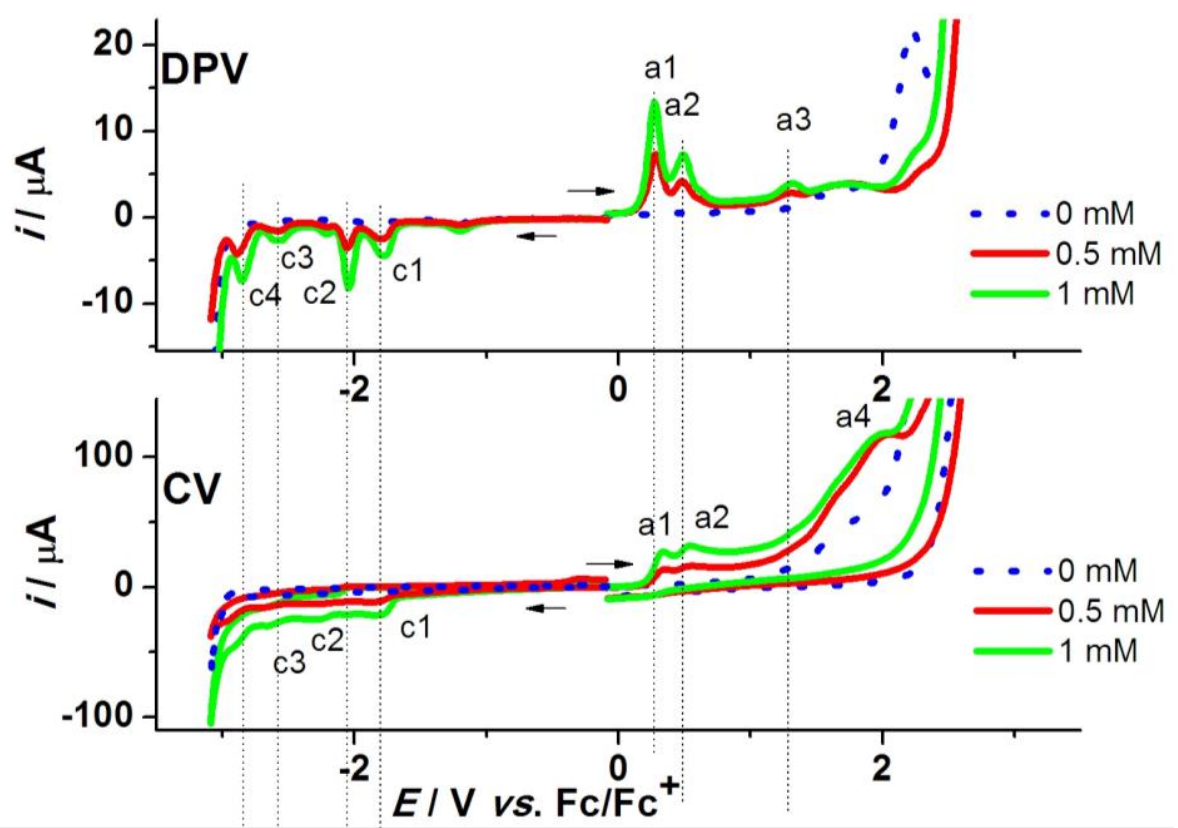

Figure 2. $D P V(0.01 \mathrm{~V} / \mathrm{s})$ and $C V(0.1 \mathrm{~V} / \mathrm{s})$ curves at different concentrations of $L$

Figure 3 presents RDE anodic and cathodic curves at different rotation rates $(500-1000 \mathrm{rpm})$ for $\mathbf{L}(1 \mathrm{mM})$. In comparison with DPV anodic and cathodic curves for $\mathbf{L}$ at $1 \mathrm{mM}$. RDE curves present one main anodic wave, and two main reduction waves.

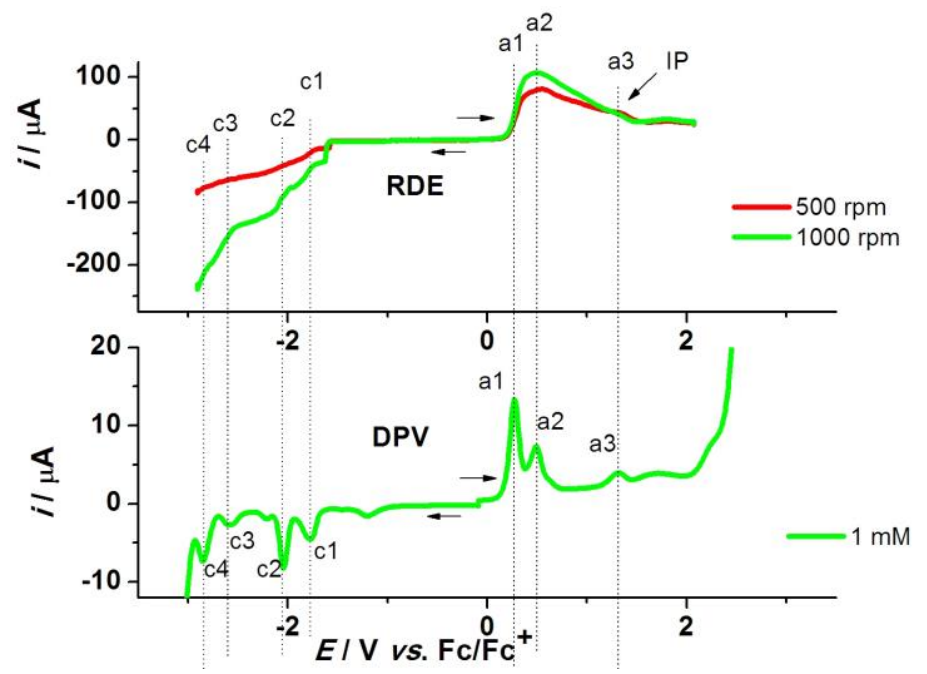

Figure 3. RDE anodic and cathodic curves at different rotation rates (up) and DPV anodic and cathodic curves (down) for L (1 mM) 
They are denoted according to the notation given for the peaks of DPV curves. In the oxidation domain the current drops suddenly after the potential of the peak a1 reaching a very low current value. This behavior is characteristic for the electrode coverage with an insulating film. One isosbestic point (IP) appears at about $1.2 \mathrm{~V}$, in the anodic domain. RDE currents increase with the rotation rate.

Figure 4 shows CV anodic and cathodic curves at different scan rates $(0.1-1 \mathrm{~V} / \mathrm{s})$ in $1 \mathrm{mM}$ solution of $\mathbf{L}$ for the first anodic and cathodic peaks. The inset shows the linear dependences of the total peak currents (for a1, a1' and c1) vs. the square root of the scan rate. The currents linearly increase with the scan rate. Even if traces of oxygen are present in solution, this increase is evident (Table 1 ).

The shape of a1 peak is characteristic for a quasi-reversible system. The diffusion coefficient of $\mathbf{L}$ $\left(D_{\mathrm{L}}\right)$ was estimated from the slope of the a1 peak current using the Randles-Sevcik equation for one electron transfer. The obtained value is quite high $\left(D_{\mathrm{L}}=4.3 \times 10^{-5} \mathrm{~cm}^{2} / \mathrm{s}\right)$, in comparison with that of a fast system such as ferrocene $\left(D_{\text {ferrocene }}=2.6 \times 10^{-5} \mathrm{~cm}^{2} / \mathrm{s}\right)[17]$.

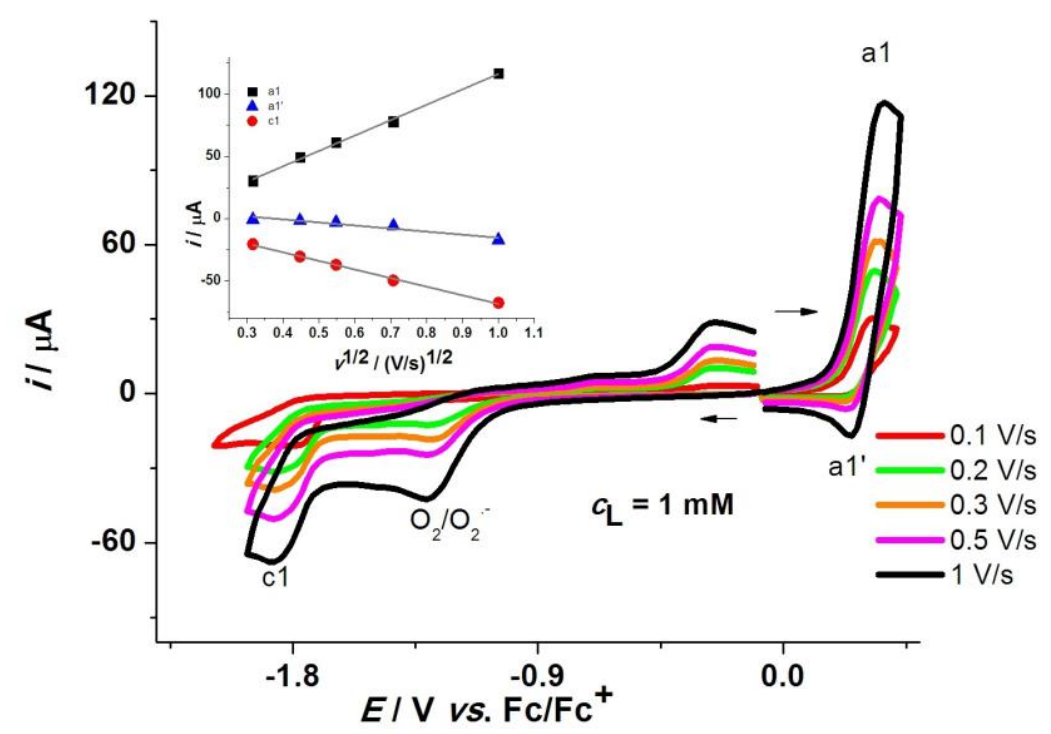

Figure 4. $C V$ anodic and cathodic curves at different scan rates for $c_{L}=1 \mathrm{mM}$; inset: linear dependences of the total peak currents vs. the square root of the scan rate

Table 1. Equations of the linear dependences of the total anodic $\left(\mathrm{i}_{p_{a}}\right)$ and cathodic $\left(\mathrm{i}_{p_{c}}\right)$ peaks currents (in $\mu A$ ) vs. the square root of the scan rate (in $V s^{-1}$ ) for $L$

\begin{tabular}{|c|c|}
\hline$i_{\mathrm{p}_{\mathrm{a} 1}} v s . v^{1 / 2}$ & $i_{p_{\mathrm{c} 1}} v s . v^{1 / 2}$ \\
\hline $\begin{array}{c}i_{\mathrm{p}_{\mathrm{a} 1}}=-7.57+123.91 v^{1 / 2} \quad \mathrm{R}^{2}=0.997 \\
i_{\mathrm{p}_{\mathrm{a} 1^{\prime}}=9.22-24.54 v^{1 / 2}} \mathrm{R}^{2}=0.892\end{array}$ & $i_{\mathrm{p}_{\mathrm{c} 1}}=0.64-69.05 v^{1 / 2}$ \\
\hline
\end{tabular}

Figure 5 shows CV anodic and cathodic curves at different scan domains in $1 \mathrm{mM}$ solution of $\mathbf{L}$. Table 2 presents the peak potentials from DPV and CV curves at $1 \mathrm{mM}$, and the peak processes assessment. In the anodic and cathodic domains, the processes are quasi-reversible or irreversible.

Table 2. Peak potentials from DPV and CV curves in $1 \mathrm{mM}$ solution of $L$ and characteristics of their processes

\begin{tabular}{cccc}
\hline Peak & DPV & $E /$ vs. Fc/Fc & Process characteristics \\
a1 & 0.27 & 0.32 & quasi-reversible \\
a2 & 0.49 & 0.53 & quasi-reversible \\
a3 & 1.31 & - & - \\
a4 & - & 1.98 & irreversible \\
c1 & -1.70 & -1.78 & irreversible \\
c2 & -2.04 & -2.30 & irreversible \\
c3 & -2.58 & -2.66 & quasi-reversible \\
c4 & -2.89 & - & quasi-reversible \\
\hline
\end{tabular}




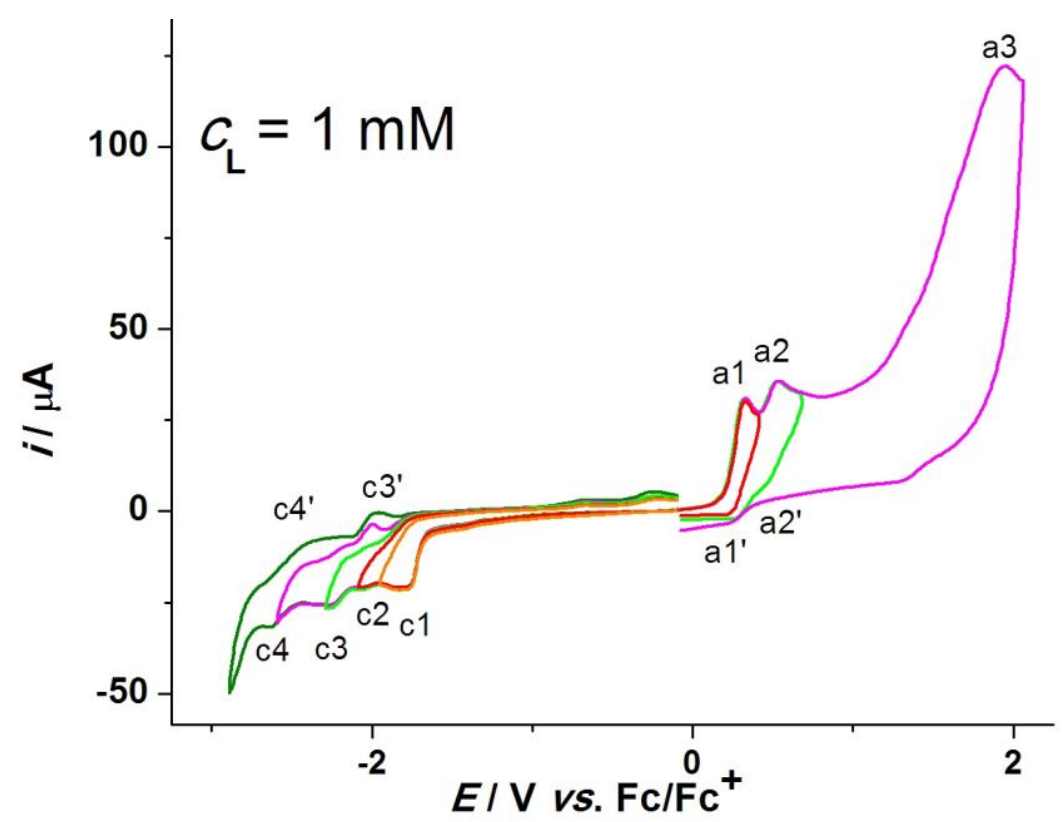

Figure 5. $C V(0.1 \mathrm{~V} / \mathrm{s})$ anodic and cathodic curves at different scan domains for $L=1 \mathrm{mM}$

Modified electrodes based on polyL

To detect heavy metal ions, such as cadmium, lead, mercury and copper, polyL glassy carbon modified electrodes were prepared. PolyL films were obtained either by successive scanning or by controlled potential electrolysis (CPE) in millimolar solutions of $\mathbf{L}$ in $0.1 \mathrm{M} \mathrm{TBAP}, \mathrm{CH}_{3} \mathrm{CN}$. Evidence on films formation on the electrode surface was obtained by transferring the modified electrodes in a solution of ferrocene $(0.5 \mathrm{mM})$ in $0.1 \mathrm{M} \mathrm{TBAP}, \mathrm{CH}_{3} \mathrm{CN}$.

Figure $6 \mathrm{~A}$ shows the $\mathrm{CV}$ curves recorded during the preparation of the modified electrode by successive scans in the domain of the anodic processes (proved to lead to insulating films). The formation of a film on the electrode surface was confirmed by transferring the modified electrode in a solution of ferrocene. Figure $6 \mathrm{~B}$ shows the $\mathrm{CV}$ curves recorded after the transfer of the modified electrode obtained by 20 successive scans (in $1 \mathrm{mM}$ solution of $\mathbf{L}$ in $0.1 \mathrm{M} \mathrm{TBAP}, \mathrm{CH}_{3} \mathrm{CN}$ ). The signal for ferrocene couple on the modified electrode is slightly diminished in intensity in comparison with that recorded on the bare electrode, indicating the formation of a thin layer film.
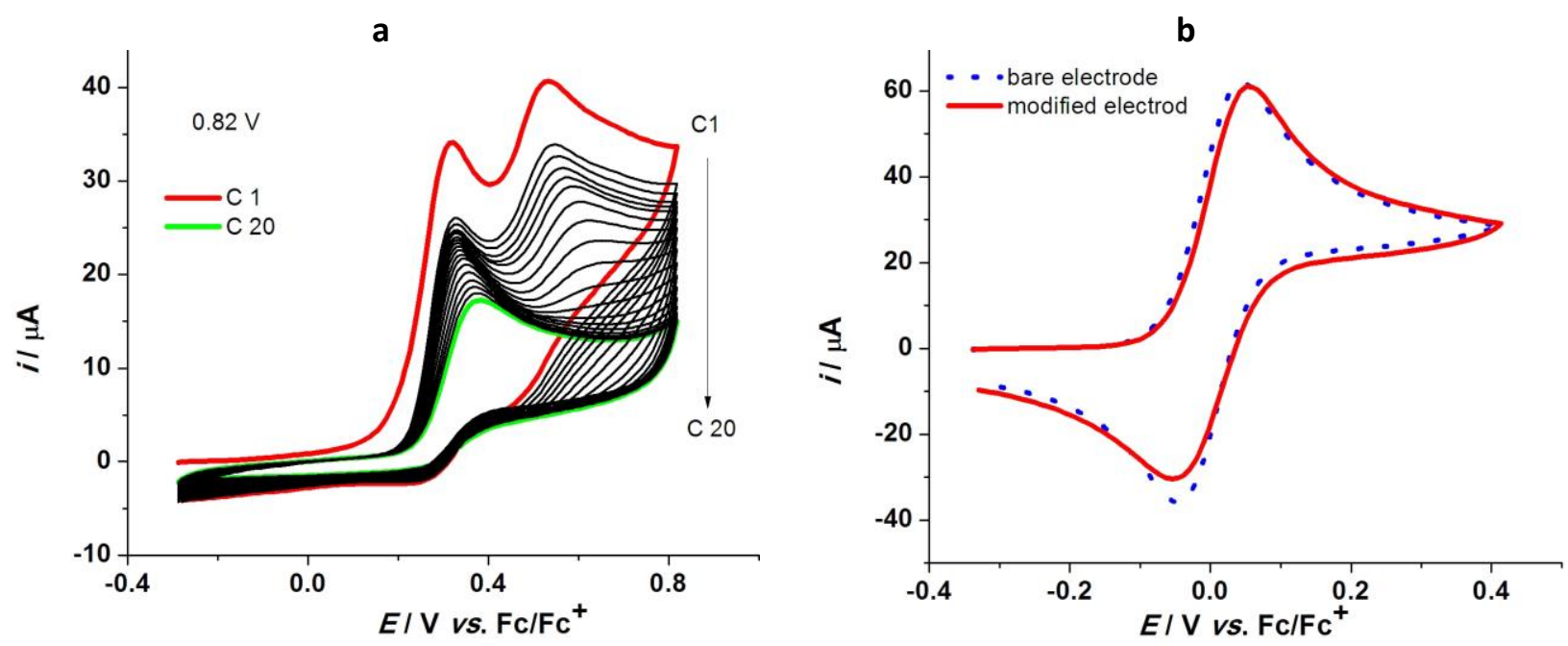

Figure 6. $C V$ curves $(0.1 \mathrm{~V} / \mathrm{s})$ during the preparation of the modified electrode by 20 successive cycles in $1 \mathrm{mM}$ solution of $\mathrm{L}$ in $0.1 \mathrm{M} \mathrm{TBAP}, \mathrm{CH}_{3} \mathrm{CN}(\mathrm{a})$; $\mathrm{CV}$ curves $(0.1 \mathrm{~V} / \mathrm{s})$ recorded in $1 \mathrm{mM}$ ferrocene solution in $0.1 \mathrm{MTBAP}, \mathrm{CH}_{3} \mathrm{CN}$ on the bare (dotted line) and modified (solid line) electrode obtained after 20 successive cycles (as shown in Fig. 6 a) (b) 
In Figure 7, CV curves in $1 \mathrm{mM}$ ferrocene solution are presented for the modified electrodes obtained by CPE at $0.82 \mathrm{~V}$ and $1 \mathrm{mC}$ (solid line) in comparison with those generated by the bare electrode (dotted line). The CV curve for the modified electrode transferred to the ferrocene solution is slightly modified relative to that for the bare electrode, which indicates the deposition of a thin layer film on the electrode surface at the charge of $1 \mathrm{mC}$.

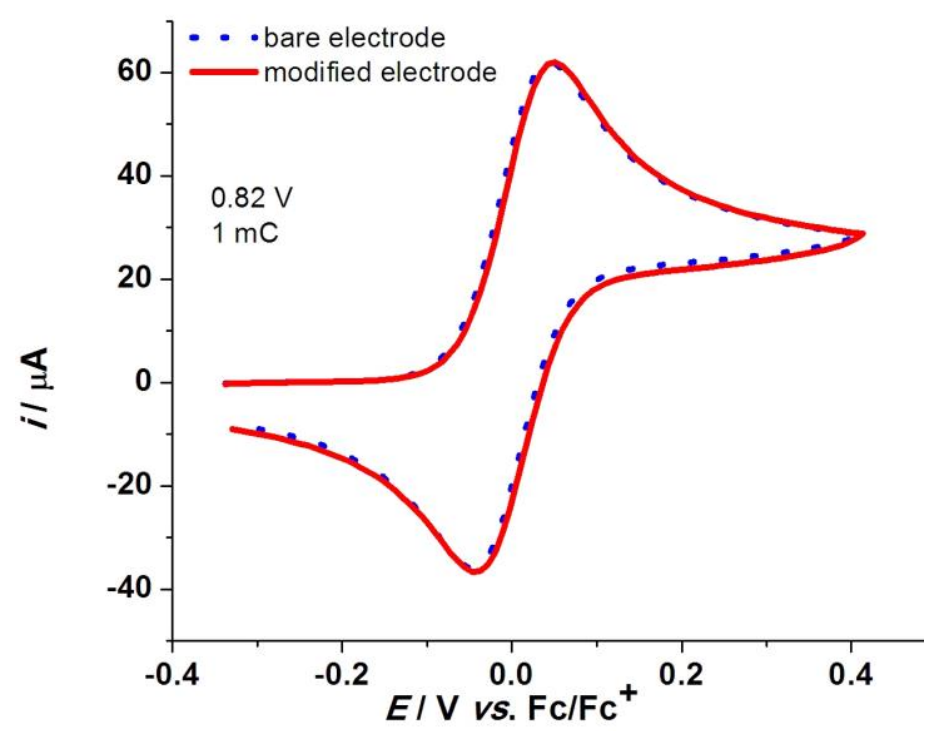

Figure 7. $\mathrm{CV}$ curves $(0.1 \mathrm{~V} / \mathrm{s})$ recorded in $1 \mathrm{mM}$ ferrocene solution in $0.1 \mathrm{M} \mathrm{TBAP}, \mathrm{CH}_{3} \mathrm{CN}$ on the bare (dotted line) and modified (solid line) electrode prepared by CPE at $0.82 \mathrm{~V}$ and $1 \mathrm{mC}$

\section{Heavy metals recognition by polyL}

The interaction between the polyL modified electrode and cations occurs through the complexing units of thiohydantoin which are connected to polyazulene structure in polyL. It depends both on $\mathrm{pH}$ and metal affinity. In basic media, it is expected that the thiohydantoin moiety ionizes forming an anion which interacts with the metal (limiting structure 1 in Scheme 1 for the ligand). A thiophilic metal, such as $\mathrm{Ag}^{+}, \mathrm{Hg}^{2+}, \mathrm{Pb}^{2+}$, etc. is expected to bind to a negative sulfur atom (limiting structure 3 in Scheme 1), while an oxophilic one to a negative $\mathrm{O}$ or $\mathrm{N}$ atom (limiting structures 1 or 2 in Scheme 1). In neutral media, as are the majority of the organic solvents, it is possible that strong interaction takes place between metal ions and negatively polarized electronegative atoms, as described.

A number of 5-(pyridylmethylidene)-2-thiohydantoins (ligand similar to that described by us) complexes with heavy metals such as $\mathrm{Cu}^{2+}, \mathrm{Ni}^{2+}, \mathrm{Co}^{2+}$, revealed a double coordination of the metal by sulfur and 3-nitrogen atoms [18]. Such complexes were observed also at other similar compounds, especially to p-dimethylbenzylidenerhodanin, which is widely used for the absorption of toxic metals in solutions with very low concentrations or for their dosage, for example $\mathrm{Ag}^{+}$ion [19], $\mathrm{Au}^{3+}, \mathrm{Hg}^{2+}$ ions [20] or other thiophilic ions [21].

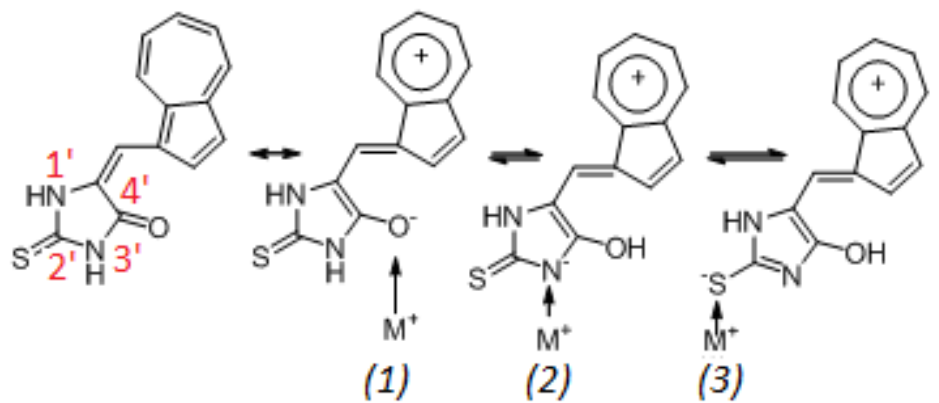

Scheme 1 
PolyL glassy carbon modified electrodes were prepared by controlled potential electrolysis at different potentials and charges. They were obtained from $1 \mathrm{mM}$ solution of $\mathbf{L}$ in $0.1 \mathrm{M} \mathrm{TBAP}, \mathrm{CH}_{3} \mathrm{CN}$ using a charge of $2 \mathrm{mC}$. The modified electrodes obtained by CPE were further introduced into the transfer cell containing $0.1 \mathrm{M}$ acetate buffer at $\mathrm{pH}$ 5.5. The electrode equilibration was done during $15 \mathrm{CV}$ cycles between -0.9 to $+0.6 \mathrm{~V}$. Then the overoxidation during $5 \mathrm{CV}$ cycles between $-0.2 \mathrm{~V}$ to and $+1.2 \mathrm{~V}$ was performed. After that, the modified electrodes were introduced in assay solutions containing a mixture of heavy metal ions at different concentrations (between $10^{-8}$ and $10^{-4} \mathrm{M}$ ), where they were maintained under magnetic stirring for 10 minutes. Finally, the modified electrodes were transferred in a cell containing $0.1 \mathrm{M}$ acetate buffer at $\mathrm{pH}$ 5.5. During a further DPV experiment, the potential of $-1.2 \mathrm{~V}$ was applied for $120 \mathrm{~s}$ (when the ions accumulated in the complexing film were reduced). Then the electrode was polarized in an anodic scan and the stripping currents for the heavy metals dissolution were recorded.

Figure $8 \mathrm{~A}$ shows the stripping curves obtained for modified electrodes prepared at different potentials using a charge of $2 \mathrm{mC}$.
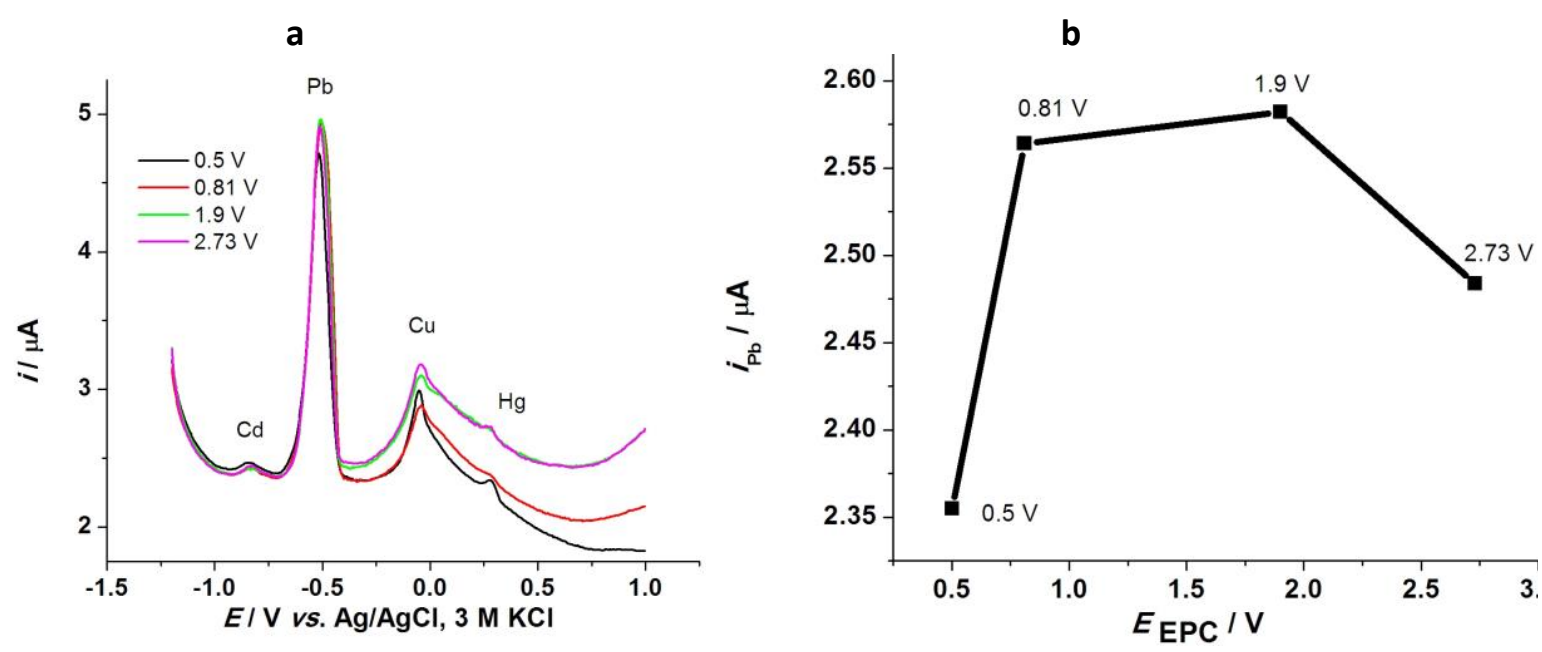

Figure 8. Anodic stripping curves recorded on polyL modified electrodes obtained by CPE at different potentials vs. Fc/Fc'. The modified electrodes where kept for 10 minutes in $10^{-4} \mathrm{M}$ solution of all ions (Cd(II),

$\mathrm{Pb}(\mathrm{II}), \mathrm{Cu}(\mathrm{II}), \mathrm{Hg}(\mathrm{II}))(\mathrm{a})$; Graph of the DPV peak currents for Pb(II) vs. CPE potential (V) at which the electrodes were modified for a thickness corresponding to $2 m C$ (b)

The heavy metals appear at the following potentials: $E_{\mathrm{Cd}}=-0.83 \mathrm{~V} ; E_{\mathrm{Pb}}=-0.50 \mathrm{~V} ; E_{\mathrm{Cu}}=-0.05 \mathrm{~V}$; $E_{\mathrm{Hg}}=+0.24 \mathrm{~V}$. The recognition of all cations was possible in the order: lead $>$ copper $>$ cadmium $>$ $>$ mercury. For the films of $2 \mathrm{mC}$ the best response in detection of lead was obtained for the films prepared at $0.81 \mathrm{~V}$ or at $1.9 \mathrm{~V}$ (Fig. 8B).

Figure 9A shows the stripping curves obtained on the modified electrodes after their introduction into solutions containing mixtures of heavy metal cations at different concentrations (between $10^{-8}$ and $10^{-4} \mathrm{M}$ ). Figure 9B provides linear dependences of DPV stripping currents on heavy metal ions concentrations in accumulation solutions. All the cations were recognized at concentrations higher than $10^{-5} \mathrm{M}$. The stripping currents increase with concentration values lower than $10^{-5} \mathrm{M}$. For higher concentrations, the stripping current values decrease or remain constant, indicating a saturation of the binding sites. At a lower concentration $\left(10^{-7} \mathrm{M}\right)$, only lead was detected. Their analytical signal values vary in the following order: lead > copper> mercury> cadmium. When using this polyL modified electrode, lead shows the best response from all the investigated cations.

Figure 10A shows the stripping curves obtained by applying the standard addition method on glassy carbon electrodes modified by CPE at $0.81 \mathrm{~V}, 2 \mathrm{mC}$ (in $1 \mathrm{mM}$ ). The solutions with the 
concentration of $10^{-6} \mathrm{M}$ mixture of $\mathrm{Cd}$ (II), $\mathrm{Cu}$ (II), $\mathrm{Hg}$ (II), $\mathrm{Pb}$ (II) and various concentrations of $\mathrm{Pb}$ (II) (between $2 \times 10^{-6} \mathrm{M} \mathrm{Pb}(\mathrm{II})$ and $6 \times 10^{-6} \mathrm{M} \mathrm{Pb}(\mathrm{II})$ ) were examined.
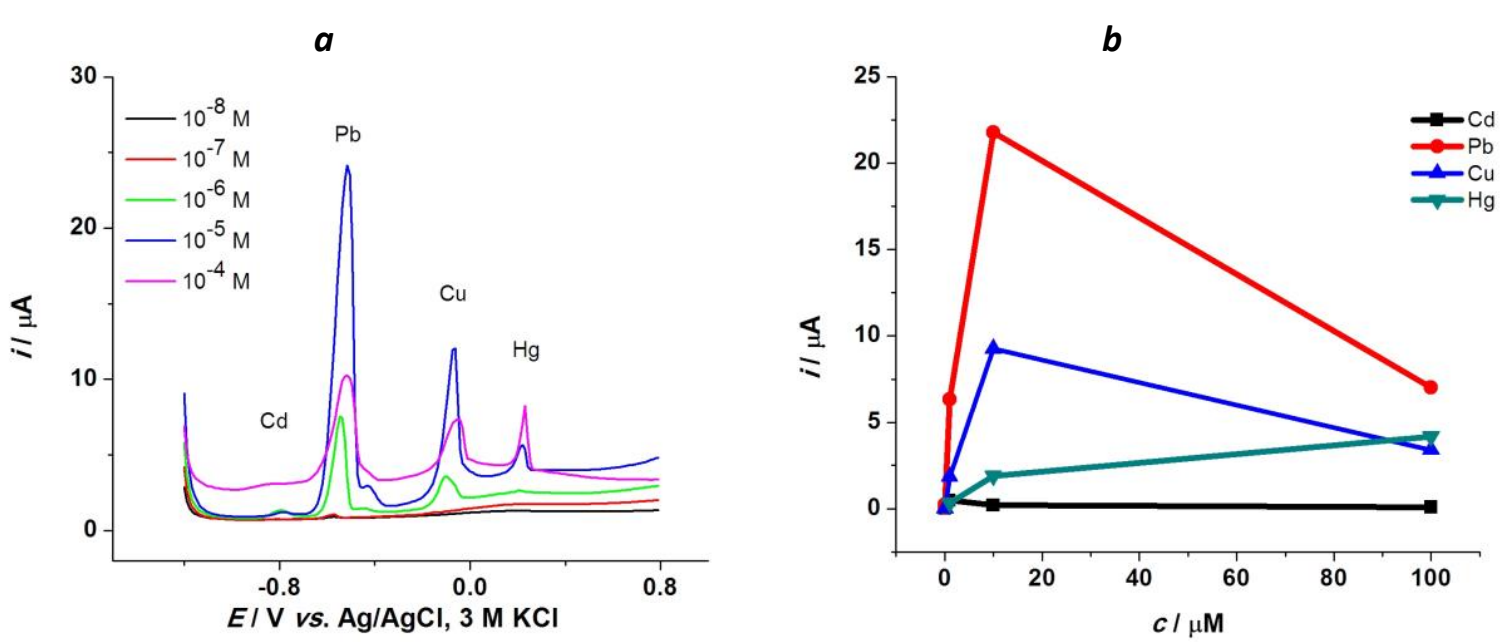

Figure 9. Anodic stripping curves recorded in acetate buffer at $\mathrm{pH} 5.5$ on polyL modified electrodes after their immersion in solutions containing different concentrations of $\mathrm{Cd}(I I), \mathrm{Pb}(\mathrm{II}), \mathrm{Cu}(\mathrm{II})$ and $\mathrm{Hg}(\mathrm{II})$ ions in water (accumulation time $10 \mathrm{~min}$ ); the modified electrodes were obtained by CPE (0.81 V vs. Fc/Fc $2 \mathrm{mC}$ )

(a); Dependences of the DPV stripping currents on heavy metal ions concentrations (b)
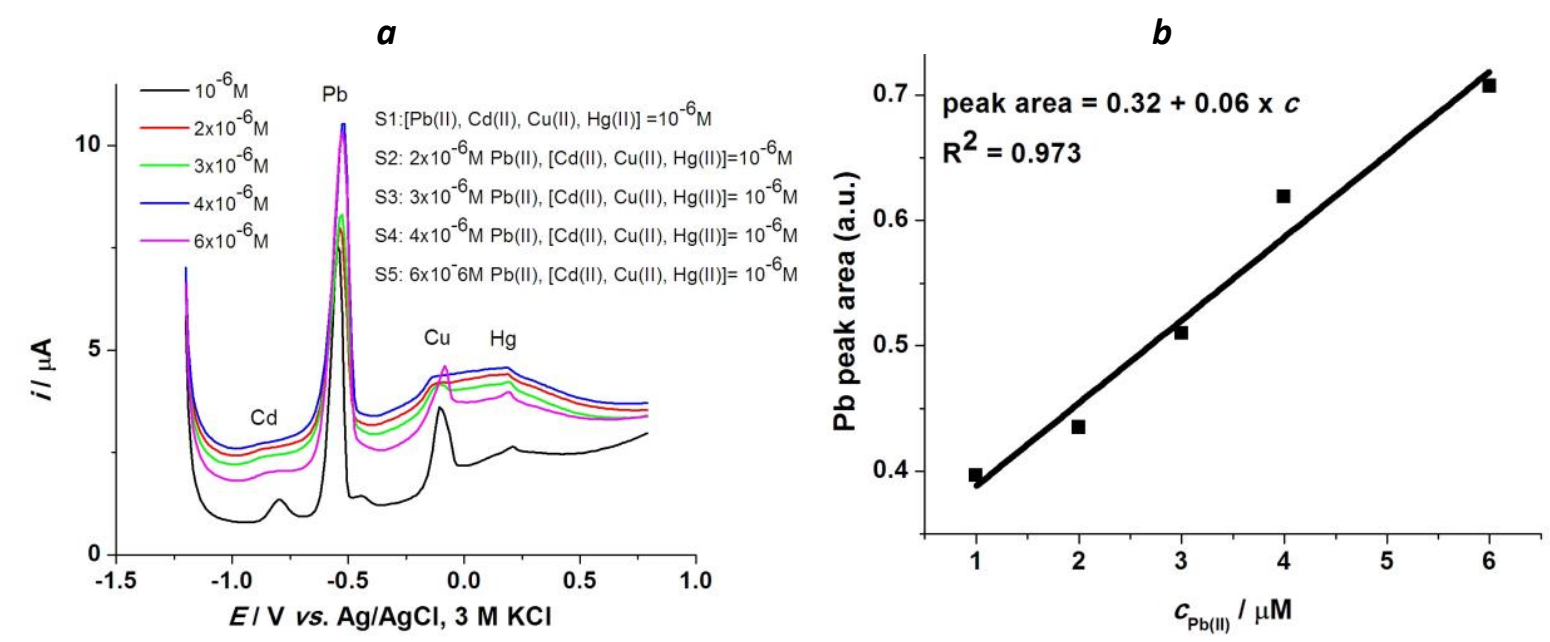

Figure 10. Anodic stripping curves recorded in acetate buffer at $\mathrm{pH} 5.5$ on polyL modified electrodes after their immersion in solutions containing different concentrations of $P b(I I)$ (between $10^{-6}$ and $6 \times 10^{-6} \mathrm{M}$ ) and a constant concentration of $\mathrm{Cd}(\mathrm{II}), \mathrm{Cu}(\mathrm{II})$ and $\mathrm{Hg}(\mathrm{II})\left(10^{-6} \mathrm{M}\right)$ ions in water (accumulation time $\left.10 \mathrm{~min}\right) ;$ the modified electrodes were obtained by CPE (0.81 V vs. $\left.F c / F c^{+}, 2 \mathrm{mC}\right)(a)$; Dependences of the DPV Pb peak stripping area vs concentration of $P b$ in accumulation solution (b)

Figure $10 \mathrm{~B}$ shows the graph of the $\mathrm{Pb}(\mathrm{II})$ peak area at different concentrations of $\mathrm{Pb}(\mathrm{II})$ in the accumulation solution. A linear increase of the peak area for lead ions is noticed (correlation coefficient 0.973).

\section{Conclusions}

The electrochemical characterization of (Z)-5-((5-isopropyl-3,8-dimethylazulen-1-yl)methylene)2-thioxo-imidazolidin-4-one (L) was performed by cyclic voltammetry, differential pulse voltammetry and rotating disk electrode methods. The anodic and cathodic processes specific for $\mathbf{L}$ have been characterized and the conditions for obtaining electrodes modified with $\mathbf{L}$ were identified. The films formation on the surface of the electrode was confirmed by the transfer of modified electrodes in ferrocene solutions. Chemically modified electrodes were prepared by electropolymerization of $\mathbf{L}$ at potentials of the second oxidation peak and tested for heavy metal 
cations recognition. When using the polyL modified electrode, lead showed the best response of all the investigated cations, followed by copper, cadmium, and mercury. This is a promising result for cations recognition using CMEs, since there is a reduced number of stripping sensors for heavy metal ions being based on CMEs among other materials.

Acknowledgements: The authors gratefully acknowledge the financial support of the Romanian National Authority for Scientific Research, UEFISCDI, under grant PN-III-P1-1.1-TE-2016-0860 contract no. 114/2018.

\section{References}

[1] E. M. Ungureanu, A.C. Razus, L. Birzan, M. S. Cretu, G. O. Buica, Electrochimic Acta 53 (2008) 70897099.

[2] I. G. Lazar, E. Diacu, G.-L. Arnold, E.-M. Ungureanu, G.-O. Buica, L. Birzan, Bulgarian Chemical Communications 49 (2017) 227-232.

[3] F. Wang, Y. H. Lai, M. Y. Han, Macromolecules 37 (2004) 3222-3230.

[4] G.-O. Buica, E. M. Ungureanu, L. Birzan, A. C. Razus, L. R. Mandoc (Popescu), Journal of Electroanalytical Chemistry 693 (2013) 67-72.

[5] G.-O. Buica, I.-G. Lazar, L. Birzan, C. Lete, M. Prodana, M. Enachescu, V. Tecuceanu, A. B. Stoian, E. M. Ungureanu, Electrochimica Acta 263 (2018) 382-390.

[6] G. G. Vasile, G. L. Arnold, G. O. Buica, E. Diacu, E. M. Ungureanu, C. Dinu, Revista De Chimie (Bucharest) 69 (2018) 21-26.

[7] I. G. Lazar, E. Diacu, G.-G. Vasile, E. M. Ungureanu, A. A. Ivanov, Revista De Chimie (Bucharest), 69 (2018) 2311-2314.

[8] G.-O. Buica, A.A. Ivanov, I.-G. Lazar, G.-L. Tatu, C. Omocea, L. Birzan, E. M. Ungureanu, Journal of Electroanalytical Chemistry (2018) DOI: 10.1016/j.jelechem.2019.113351.

[9] L. Makedonski, K. Peycheva, M. Stancheva, Food Control 72 (2017) 313-318.

[10] M. N. Islam, H.-Y. Jung, J. H. Park, Journal of Environmental Management 163 (2015) 262-269.

[11] L. Wang, A. Li, Y. Chang, Chemical Engineering Journal 297 (2016) 1-10.

[12] A. K. Malik, V. Kaur, N. Verma, Talanta 68 (2006) 842-849.

[13] M. Pourjavid, M. Arabieh, S. Yousefi, A. Sehar, Microchemistry Journal 129 (2016) 259-267.

[14] M.-C. Radulescu, A. Chira, M. Radulescu, B. Bucur, M. P. Bucur, G. L. Radu, Sensors 10 (2010) 1134011351.

[15] G. L. Arnold, Sensors based on azulene modified electrodes for testing metals in waters, University Politehnica of Bucharest (2017) PhD Thesis.

[16] L. Birzan, M. Cristea, C. C. Draghici, V. Tecuceanu, M. Maganu, A. Hanganu, A. C. Razus, G. O. Buica, E. M. Ungureanu, Dyes and Pigments 131 (2016) 246-255.

[17] Alan M. Bond, Keith B. Oldham, Graeme A. Snook, Analytical Chemistry 72 (2000) 3492-3496.

[18] E. K. Beloglazkina, A. G. Majouga, I. V. Yudin, N. A. Frolova, N. V. Zyk, V. D. Dolzhikova, A. A. Moiseeva, R. D. Rakhimov, K. P. Butin, Russian Chemical Bulletin 55 (2006) 1015-1027.

[19] E. Yavuz, Ş.e Tokalıoğlu, S. Şahan, Journal of the Brazilian Chemical Society 24 (2013) 736-742.

[20] B. Hofmann, K. H. Lieser, Die Angewandte Makromolekulare Chemie 142 (1986) 137-145.

[21] M. T. Certi Mazza, L. De Cicco, G. De Rosa, R. De Rosa, R. Caramazza, Bollettino della Societa Italiano di Biologia Sperimentale 72 (1996) 79-86.

(C)2019 by the authors; licensee IAPC, Zagreb, Croatia. This article is an open-access article distributed under the terms and conditions of the Creative Commons Attribution license (http://creativecommons. org/licenses/by/4.0/) 